\title{
Future vision of advanced oxidation process and its immediate efficacy-a deep, insightful comprehension and a far-reaching review
}

\author{
Sukanchan Palit \\ Department of Chemical Engineering, University of Petroleum and Energy Studies, \\ Post Office-Bidholi via Premnagar, Dehradun - 248007, Uttarakhand, India \\ Telephone Nos. - 0091-8958728093, 0091-3324026947 \\ E-mail address: id-sukanchan68@gmail.com , sukanchan92@gmail.com
}

\begin{abstract}
Environmental engineering is moving briskly and steadily from one challenging phase to another. The world of challenges are immense as well as far-reaching. Advanced oxidation processes today stands in the midst of immense scientific vision, scientific understanding and invincible scientific challenges. The effectivity of degradation quality of ozone and hydroxyl radicals is outstanding and path-breaking. Environmental concerns and subsequent environmental regulations are the burning issues of our present day civilization. Novel separation processes as well advanced oxidation techniques are the plausible solutions for zero-discharge norms and effective environmental engineering paradigm. The question of effective environmental engineering techniques comes into the horizon of a scientist's mind. Amongst the advanced oxidation techniques, ozonation or ozoneoxidation stands today in the new millennium as the most effective environmental engineering techniques. Wastewater treatment and provision of clean drinking water are unquestionably the primordial issues of present day mankind and the ever-alert civil society. The visionary challenges are moving from one avenue of environmental disaster to another. Environmental disaster - both manmade as well as natural has plunged our civilization to unending catastrophe. These environmental calamities are harbingers of more immense and impending environmental disasters. The scientific paradigm and the scientific domain needs rethought and needs to be restructured. In the face of these immense environmental calamities, the thrust areas of novel separation processes and advanced oxidation needs immense retrospection. In such a critical juncture of history and time, this treatise effectively addresses the questions of zero-discharge norms with respect to new discoveries in the field of advanced oxidation processes particularly the field of ozonation.
\end{abstract}

Keywords: oxidation; vision, environment; dye; future; introspection

\section{INTRODUCTION}

The field of advanced oxidation processes is widely expanding in this generation of environmental engineering restrictions. Environmental engineering paradigm is ushering in a new era of immense and versatile challenges. Environmental restrictions and regulations are creating a new age of more improved environmental engineering techniques. In such a critical juncture of human civilization, the introspection towards novel separation processes and 
advanced oxidation techniques needs to be effectively addressed. The challenges behind scientific endeavor, scientific determination and scientific endurance are far and visionary. The future of the advanced oxidation processes are moving through one age of visionary standing to another. In the history of science and engineering, the contribution of environmental engineering stands as a primordial backbone and a colossus in addressing to the needs of human society and human mankind. The need of the hour that is the water shortage and water crisis needs to be restructured.

A wide gamut of organic compounds is detected in industrial and municipal wastewater. Some of these compounds (both synthetic organic chemicals and naturally occurring substances)pose severe problems in biological treatment systems due to their resistance to biodegradation or/and toxic effects on microbial processes. As a result, the use of alternate treatment technologies, aiming to mineralize or transform refractory molecules into others which could be further biodegraded, is a matter of immense concern. Among them, advanced oxidation processes (AOPs) have already been used for the treatment of wastewater containing recalcitrant organic compounds such as pesticides, surfactants, colouring matters, pharmaceuticals and endocrine disrupting chemicals. The vision of advanced oxidation techniques and its application is effective, far-reaching and immensely proven over the last three decades.

\section{RESULTS AND DISCUSSION}

\section{Advanced oxidation processes and next generation scientific pursuit and scientific understanding}

Advanced oxidation processes is one of the major environmental engineering techniques to degrade wastewater in our present day civilization. The challenges are far and wide. But the scientific determination is leading our present day civilization to a realm of unending success and unsurpassed greatness. Advanced oxidation processes is the next generation environmental engineering technique. Scientific barriers are unconquerable and invincible. But efficacy leads to immense success. The barriers of science and engineering are inevitably surpassed with succeeding generations at every turn of discovery and major inventions.

\section{Vision of advanced oxidation process and its long term effectivity}

The vision of a scientist is versatile and inspiring. Research, resource and creation has compelled a scientist to strive further. The world of chemical engineering and environmental engineering is ushering in a new global era and a new world of scientific intuition is emerging. The vision of advanced oxidation process, nanofiltration and bubble column reactor is awesome, evergrowing and far-reaching. The basic advantages of the tool which is that of bubble column reactor is that it has feasible hydrodynamics and excellent heat and mass transfer characteristics. Extensive research work is done by scientists, researchers and learned scientific community throughout the scientific spectrum. The world of unknown opens up a new age and a new vision. Environmental restrictions and stringent regulations are the forerunners of the scientific vision.

Advanced oxidation processes (AOP's) comprise of a promising and challenging technology for the treatment of wastewaters containing non-easily removable organic compounds. All AOP are designed to produce hydroxyl radicals. It is the hydroxyl radicals that act with high efficiency to destroy organic compounds. AOP combine ozone $\left(\mathrm{O}_{3}\right)$, ultraviolet $(\mathrm{UV})$, 
hydrogen peroxide $\left(\mathrm{H}_{2} \mathrm{O}_{2}\right)$ and/or catalyst to offer a powerful water treatment solution for the reduction and/or removal of residual organic compounds as measured by COD, BOD or TOC. This review paper delineates in details a general review of efficient advanced oxidation processes developed to decolorize and/or degrade organic pollutants for environment protection $^{1,2,3,4}$.

\section{Integrated advanced oxidation techniques-present and future objectives and vision}

Integrated advanced oxidation processes is the next generation science and technology of environmental engineering and wastewater treatment ${ }^{1,2,3,4}$. It is an extremely proven and visionary technology. The vision of the application area of advanced oxidation process will inevitably open up new vistas in the visionary domain of intuition and innovation. Integrated advanced oxidation processes are in the verge of a new era of optimism, hope and scientific vision. History of environmental engineering and history of advanced oxidation processes today stands as an effective tool towards immense and visionary scientific understanding and scientific judgement. Human mankind will have immense help and be a harbinger of scientific validation to civil society with new innovation and new discoveries in years to come.

\section{Integrated advanced oxidation processes for wastewater treatment-the next generation technology}

Disposal of waste and wastewater treatment stands today in the midst of immense concern and hopeful vision. History of science and technology is ever growing, more inspiring and burgeoning at a rapid and progressive pace. Man's vision is once again restructured and re-envisioned with the inception of new technology and progressive thoughts. Frontier surpassing technology is the vision of future and waste water treatment techniques will surely validate man's progress and surge towards a better tomorrow. The visionary implications of the application of advanced oxidation process is wide and proven. The major thrust area is the targeted vision towards an effective tertiary treatment.

\section{Main thrust area of advanced oxidation processes- degradation of dyes and itspurposeful vision}

Environmental restrictions and ecological imbalance has urged scientific domain and scientific understanding to diversify knowledge and intuition. Dyes are the vicious product of textile industrialization ${ }^{3,8}$. The question of environmental sustainability is at stake and in the brink of unsurpassed disaster. Textile wastewater includes a large variety of dyes and chemical additions that make the environmental challenge for textile industry not only as liquid waste but also in its chemical composition. Main pollution in textile wastewater came from dyeing and finishing processes. These processes require the input of a wide range of chemicals and dyestuffs, which generally are organic compounds of complex stature ${ }^{3,8}$. Major pollutants in textile wastewaters are high-suspended solids, chemical oxygen demand, heat, colour, acidity and other soluble substances. The removal of colour from textile industry wastewater and dye manufacturing industry wastewaters represents a major and colossal concern. In addition, only $47 \%$ of 87 of dyestuff are biodegradable. It has been documented that residual colour is usually due to insoluble dyes which have low biodegradability as reactive blue 21, direct blue 80 and vat blue with COD/BOD ratio of 59.0, 17.7 and 10.8 respectively. Conventional oxidation treatment have found difficulty to oxidize dyestuffs and complex structure of organic compounds at low concentration or if they are especially 
refractory to the oxidants. To address and ease the stated problems, advanced oxidation processes (AOPs) have been developed to generate hydroxyl free radicals by different techniques. AOPs processes are a combination of ozone $\left(\mathrm{O}_{3}\right)$, hydrogen peroxide $\left(\mathrm{H}_{2} \mathrm{O}_{2}\right)$ and UV radiation, which showed the greatest promise to treat textile wastewater. These oxidants effectively decolorized dyes, however did not remove COD completely.

The goal and mission of an AOP design is to generate and use hydroxyl free radicals (HO') as strong oxidant to destroy compound that cannot be oxidized by conventional oxidant. Table 1 shows the relative oxidation potentials of several oxidizers. Advanced oxidation processes are characterized by production of $\mathrm{OH}$ ' radicals and selectivity of attack which is a useful attribute for an oxidant. The versatility of AOP is also enhanced by the fact that they offer different possible ways for $\mathrm{OH}$ ' radicals.

Table 1. Oxidizing potential of conventional oxidizing agents.

\begin{tabular}{|c|c|c|}
\hline Oxidizing Agent & $\begin{array}{c}\text { Electrochemical oxidation } \\
\text { (EOP), V }\end{array}$ & EOP relative to Chlorine \\
\hline Fluorine & 3.06 & 2.25 \\
\hline Hydroxyl radical & 2.80 & 2.05 \\
\hline Oxygen (atomic) & 2.42 & 1.78 \\
\hline Ozone & 2.08 & 1.52 \\
\hline Hydrogen peroxide & 1.78 & 1.30 \\
\hline Hypochlorite & 1.49 & 1.10 \\
\hline Chlorine & 1.36 & 1.00 \\
\hline Chlorine dioxide & 1.27 & 0.93 \\
\hline Oxygen (molecular) & 1.23 & 0.90 \\
\hline
\end{tabular}

The vision of application of advanced oxidation processes are wide and far-reaching. The integration of various processes ushers in a new scientific vision and a new scientific understanding in decades to come. The world of challenges is gearing up to newer methodologies and newer phases of scientific understanding and judgement.

\section{Ozonation and integrated advanced oxidation processes-its vision for the future}

Ozone is a powerful oxidant agent for water and wastewater. Once dissolved in water, ozone reacts with a great number of organic compounds in two different ways: by direct oxidation as molecular ozone or by indirect reaction through formation of secondary oxidants like hydroxyl radical. Ozone application can be generalized into two; a powerful disinfection and a strong oxidant to remove colour and odour, eliminating trace toxic synthetic organic compounds and assisting in coagulation.

Ozonation stands today as an effective and far-reaching technique to degrade industrial wastewater especially textile industry wastewater. The efficiency and effectivity of ozonation 
is well known and proven. Environmental engineering is steadily and steadfastly moving into a new era of invention and innovation. Along with ozonation technique, integrated advanced oxidation processes will go a long way to unravel the intricate understanding of the future of environmental engineering. The chemistry of ozonation will open up wide doors of intuition and innovation in the deep and keen understanding of novel advanced oxidation processes. The vision for the future is absolutely wide and bright. History of science, technology and environmental engineering will be a visionary witness in the domain of understanding of chemical oxidation.

\section{Wastewater treatment, environmental sustainability, future directions and the definitive vision for the future}

Wastewater treatment stands as one of the major issues of present generation environmental engineering paradigm ${ }^{1,2,3,4}$. The world of challenges are immense, wide and many. The visionary path towards an effective environmental engineering technique has urged mankind to strive towards non conventional techniques and novel separation processes. The concept of environmental sustainability needs to be restructured and revamped. Zero discharge norms and stringent environmental engineering norms has urged mankind's scientific domain to develop and investigate newer directions of technology. Wastewater treatment is moving in the right direction of human endeavour.

Wastewater treatment and environmental sustainability have an umbilical cord in today's human generation. The world of challenges are huge but visionary implications are surpassing many scientific frontiers. History of mankind and history of science and technology will witness a new era with the turn of each decade and the inevitable evolution of time. Man's vision will be emboldened with every discovery and every successful endeavour in the field of novel separation process.

\section{Present and future of advanced oxidation processes}

Advanced oxidation processes stands today on the verge of a new generation of hope and destiny. Environmental engineering techniques is burgeoning in a new era and new dimension. Problems of wastewater treatment are a boon to disaster to human mankind. Three Mile Islands, Chernobyl and Bhopal are examples of immense disasters for the future scientific generations to learn from. Future scientific determination should be targeted in a vicious and vehemented manner. Challenges are wide and many but determination to excel will surely pave way towards a new generation of hope and destiny.

\section{Ozonation-the next generation avenue of success}

Ozonation or integrated advanced oxidation processes is the next generation science and engineering with potential of immense proportions. Avenues of success, strong and wide, needs restructuring and rebuilding in view of the immense challenges which lie in the future dimensions of a distant horizon. Ozonation is effective and meets immensely zero discharge norms of a nation's stringent environmental regulations. Ozonation or ozone-oxidation is a fundamental science of the wider branch of advanced oxidation process which can provide immense scientific oppurtunities and scientific innovations. Ozone oxidation with the help of its degradation tools is highly effective in presence of hydroxyl radicals and ozone radicals.

According to Mehmat and Hassan $(2002)^{13}$, ozonation $\left(300 \mathrm{mg} / \mathrm{m}^{3}\right)$ increased the biodegradability index of textile wastewater by 1.6 times. Jianging and Tingwei $(2001)^{12}$ documented 11-66 times increase in biodegradability index for wastewater containing azo 
dye, while this increment reached to 80 times for wastewater containing simulated reactive dye and reactive yellow $84\left(\right.$ Koch et al, 2002) ${ }^{14}$. This findings revealed that increase in biodegradability index was influenced by type and concentration of dye.

\section{Global water crisis and vision for the future}

Global water crisis is bringing our civilization to the brink of unending disaster and unsurpassed catastrophe. Global vision from the civil society will surely bring an end to this inevitable disaster. Mankind will be a genuine witness to the cause and effect relationship of the great endeavour. Future pursuits and future thrust areas in the avenues of research in the domain of tackling global water crisis needs to be restructured, rebuild and reinvented. The vision which lie before the distant horizon in the scientific domain is awesome and needs to be restructured. Global water crisis is moving towards a new generation of science and technology $5,6,7,8$.

\section{Vision, objectivity and ultimate mission in scientific endeavour}

Vision and objective of scientific determination of the endeavour in the domain of advanced oxidation process is immense and versatile. Ideas and innovations are wide and many. The following treatise explains and explores the vast and versatile areas of advanced oxidation processes. The objective and determination of advanced oxidation processes is revealing itself at every turn of a decade. Scientific judgement is varied and effective. Endeavour in such a critical juncture of history and time needs to be re-justified and reaffirmed. Degradation of recalcitrant chemicals is the primordial issue of the day. The crux of the matter needs to be re-assessed in the view of the immense and wide environmental restrictions and stringent regulations.

\section{Important and instinctive scientific endeavour in the field of advanced oxidation process}

Scientific endeavour has no specific boundaries. The vision is immense and bright. Advanced oxidation process stands today as an effective environmental engineering technique in tackling immense and mind boggling scientific issues. The objectivity cannot be overlooked. The absolute mission of the application area of advanced oxidation technique or the integration of various advanced oxidation processes will in future surpass inevitable scientific boundaries. In every turns and moves of human scientific history, the mankind is faced with immense and unassuming challenges. The question of validation of human knowledge moves parallelly with scientific endeavour and immense scientific determination.

Al-Kdasi et al. (2004) ${ }^{3}$ dealt with incisive thought on treatment of textile wastewater by advanced oxidation process in a detailed review. The authors touched upon detailed research in this domain. The governing field encompasses textile wastewater characteristics, various advanced oxidation processes, the importance of ultraviolet light, the importance and detailed analysis on the application of ozone as an advanced oxidation process, importance of integrated ozone and ultraviolet application, integration of hydrogen peroxide and ultraviolet light, a salient detail on peroxone application and finally the integrated ozone-hydrogen peroxide - ultraviolet technique(advanced oxidation processes. The vision and objective of this review paper elucidates the uniqueness of this technique over other non-biodegradable techniques and as a viable alternative. An overview of basis and treatment efficiency for different AOPs are considered and presented according to their specific features.

Stasinakis et al. (2008) $)^{8}$ enlivened the ongoing treatise of advanced oxidation processes in a review of use of selected advanced oxidation processes(AOP's) for wastewater 
treatment. The aim of the study was to review the use of titanium dioxide/UV light process, hydrogen peroxide/UV light process and Fenton's reactions in wastewater treatment. The salient features and the visionary crux of this study elucidates titanium dioxide process, UV light process, hydrogen peroxide, UV light process, Fenton's reactions and a detailed future perspectives and future scientific understanding.

Joseph et al. (2009) ${ }^{9}$ detailed in a lucid review the importance of sonophotocatalysis in advanced oxidation process. Sonophotocatalysis involves the combination of ultrasonic sound waves, ultraviolet radiation and semiconductor photocatalyst to enhance a chemical reaction by the formation of free radicals in aqueous systems. A detailed research of published reports was done and analyzed in this paper with respect to sonication, photocatalysis and advanced oxidation processes.

Huber et al. $(2003)^{10}$ dealt with the oxidation of pharmaceuticals during ozonation and advanced oxidation processes. This study examines with affirmative tone the oxidation of pharmaceuticals during conventional ozonation and advanced oxidation processes (AOPs) applied in drinking water treatment. Esplugas et al. $(2007)^{11}$ described in a review paper the importance of ozonation and advanced oxidation technologies to remove endocrine disrupting chemicals (EDCs) and pharmaceuticals and personal care products (PPCPs) in water effluents. Data concerning degradation of PPCPs and EDCs by means of AOPs reported during the period January 2000-May 2007 are evaluated with detailed analysis in this paper. In this paper with a compelling analysis the author delineates the importance of ozonation as a visionary approach to tackle wastewater treatment.

Gogate et al $(2004)^{4}$ dealt in a review of imperative technologies for wastewater treatment and oxidation technologies at ambient conditions. In today's present day civilization, novel and newer technologies are needed to eradicate the immense issue of industrial wastewater problem. Due the increasing presence of molecules, refractory to the microorganisms in the wastewater stream, the conventional biological methods cannot be used for complete treatment of the effluent and hence introduction of newer technologies to degrade these refractory molecules into smaller molecules which can be further oxidized by biological methods are extremely imperative and visionary. Gogate et al highlighted five different oxidation processes operating at ambient conditions for example cavitation, photocatalytic oxidation, Fenton's chemistry and ozonation, use of hydrogen peroxide.

The upshot of the immense endeavour in the field of advanced oxidation process related in this treatise tries to analyse the efficacy of this environmental engineering technique. Application areas are not demarcated but integrated. Treatment of pharmaceutical wastewater is a new and visionary technique. Sonophotocatalysis integrated with advanced oxidation process needs to be addressed in an effective and holistic manner. A deep insight into different application areas of advanced oxidation process or non-conventional oxidation is highlighted in a vehement manner.

\section{Vision, aim and immense scientific determination in the field of advanced oxidation processes}

Advanced oxidation processes are the next generation science and future technology. The question of water treatment and wastewater treatment looms large over the scientific horizon. Man's vision should be restructured and reinvented in this field of environmental engineering. In such a today's critical juncture of history and time, the vision needs to be vehemently explored. Immense scientific determination and restructuring of the scientific thought process will go a long way in exploring the unknown. 
Exploration and comprehension with retrospection needs to be addressed at every turn of a decade in the present century. Mankind's vision needs to be revamped in addressing the application potentials of non-conventional oxidation techniques and novel separation processes. The surge and striving in scientific endeavour are far-reaching and the fruits of science and technology are surpassing visionary frontiers. History of advanced oxidation processes will usher in a new generation of scientific thoughts in years to come.

\section{Mission statement, the progress of mankind and advancement of science and technology}

Mission and aim of human civilization needs a thorough redrafting in view of the importance of environmental regulations and restrictions. Scientific vision and scientific judgement in the application areas of advanced oxidation processes are ushering in a new generation of purposeful and definitive progress of science and technology. Man's surge and striving towards scientific endeavour are absolutely visionary. The urge to excel in scientific progress needs to be reassessed in the present scenario of the application of advanced oxidation processes. History of science and technology will be a vibrant witness to the visionary techniques of environmental engineering and industrial wastewater treatment.

\section{Upshot and summary of the entire treatise}

This treatise explores with deep and instinctive insight the future of advanced oxidation processes and its efficacy. It also examines the immense scientific contribution of past decades. The vision for the future is immensely wide and bright. The challenges needs to be more revamped with the turn of each decade. The world of challenges and the world of unsurpassed barriers needs to be revamped and reassessed with the changing face of environmental disasters and ecological imbalance. The upshot of this treatise is to address the future of advanced oxidation process and its efficacy to treat industrial wastewater.

\section{Future directions, future thoughts and future avenues of research}

Future directions and future thoughts are moving towards a new generation of understanding and immense restructuring and reinventing in the field of advanced oxidation processes $^{9,10,11}$. The question of validation of research stands as a primordial issue in environmental engineering. With such critical and crucial stance, the scientific vision will surely open up a new era of innovation in years to come. Innovations and intuitions are the unsurpassable orders of the day. History of advanced oxidation processes and innovative integrated advanced oxidation techniques needs a greater and visible outlook and instinctive vision.

\section{CONCLUSIONS}

Future directions and future dimensions of the domain of advanced oxidation processes will open up new doors of innovation and intuition in the feasible future. Mankind's objective and scientist's validation are the primordial issues in the world of environmental engineering and environmental science today. History of advanced oxidation process in the first of twentieth century needs to be restructured and revalidated. The pertinent question of environmental sustainability stands today in the midst of immense hope, determination and vision. The research plan of tomorrow needs to be reassessed and re-adjudicated with the immediate vision of zero-discharge norms and effectivity and efficiency of the advanced 
oxidation processes. Environmental sustainability and application of environmental engineering techniques have an umbilical cord linked with it. This branch of human scientific endeavour has an ultimate vision-the efficiency and effectivity of the process. The world of unsurpassable and inevitable challenges will open up a new era of extreme innovation in the field of advanced oxidation processes in decades to come. The challenges will be surely overcome if proper scientific vision is converted to strong scientific validation. Advanced oxidation process is not immature yet latent and needs to be targeted towards global environmental pollution and global environmental sustainability.

In today's present day scientific world, the vision of tomorrow is far-reaching. Scientific advancements and sustainable development are inextricably linked. The drastic challenges which will usher in a new scientific order are relevant to the human needs in the distant visionary future. Advanced oxidation processes, novel separation processes or other environmental engineering technologies will surely bridge the gap between innovation, invention and application towards human society. In such a defining stature, man's vision will be extremely realized in years to come.

\section{Acknowledgement}

The author wishes to acknowledge immensely the Chancellor, Management, Faculty and students of University of Petroleum and Energy Studies, Dehradun, India without whom this writing project would not be achieved. The author also wishes to acknowledge the contribution of past and present teachers of Department of Chemical Engineering, Jadavpur University, Kolkata, India.

\section{References}

[1] Kepa U., Stanczyk-Mazanek E., Stepniak L., Desalination 223 (2008) 187-193

[2] Zhou H., Smith D. W., Journal of Environmental Engineering Science 1 (2002) 247-264.

[3] Al-Kdasi Idris. A., Saed K., Guan C. T., The International Journal 6(3) (2004) 222-230.

[4] Palit. S., International Journal of Chem Tech Research 4(3) (2012) 862-866.

[5] Gogate P. R., Pandit A. B., Advances in Environmental Research 8 (2004) 500-551.

[6] Chiron S., Fernandez-Alba A., Rodriguez A., Garcia-Calvo E., Water Research 34(2) (2000) 366-377.

[7] Kos L., Perkowski J., Fibres and Textiles in Eastern Europe. 11(4) (2003) 43.

[8] Suty H., De Traversay C., Water Science and Technology 49(4) (2004) 227-233.

[9] Stasinakis A. S., Global NEST Journal 10(3) (2008) 376-385.

[10] Joseph C. G., Puma G. L., Bono A., Krishnaiah D., Ultrasonics Sonochemistry 16 (2009) 583-589.

[11] Huber M. M., Canonica S., Park G. Y., Gunten U. V., Environmental Science and Technology 37 (2003) 1016-1024.

[12] Esplugas S., Bila D. M., Krause L. G. T., Dezotti M., Journal of Hazardous Materials 149 (2007) 631-642.

[13] Jianging W. U., Tingwei W., Water Research 35 (2001) 1093-1099. 
[14] Mehmet F. S., Hasan Z. S., Journal of Chemical Technology and Biotechnology 77 (2002) 842-850.

[15] Koch M., Yediler A., Lienert D., Insel G., Kettrup A., Chemosphere 46 (2002) 109-113. 